\title{
Effects of PID Controller Location in the System loop of Mobile Satellite Dish Network
}

\author{
Aye Taiwo Ajiboye \\ National Centre for Agricultural \\ Mechanisation, llorin, Nigeria
}

\author{
Tunji Samuel Ibiyemi \\ Department of Electrical and \\ Electronics Engineering, \\ University of Ilorin, Ilorin, \\ Nigeria
}

\author{
Alaba John Falade \\ Department of Electrical and \\ Electronics Engineering, \\ University of llorin, llorin,
} Nigeria

\begin{abstract}
The effects of proportional-integral-derivative (PID) position controller location within the structure of network of mobile satellite dish spread all over Nigeria on system performance were investigated. The region of acceptable stability for the system was graphically determined in the integral gain, $\mathrm{K}_{\mathrm{i}}-$ derivative gain, $K_{d}$ plane for the determined value of proportional gain, $\mathrm{K}_{\mathrm{p}}$. Values for $\mathrm{K}_{\mathrm{i}}$ and $\mathrm{K}_{\mathrm{d}}$ were determined within the stability region. The determined values of $\mathrm{K}_{\mathrm{p}}, \mathrm{K}_{\mathrm{i}}$ and $K_{d}$ were slotted into the PID controller transfer function. The resulting controller was then connected to the system as series compensation and feedback compensation respectively. After putting together the composite system transfer function for uncompensated, series compensated and feedback compensated systems, they were then subjected to a step input forcing function, which yielded time domain performance indices for these systems using MATLAB as a simulation tool. The obtained time domain performance indices for the uncompensated system, series compensated system and feedback compensated system show that the series compensated system has superior performance followed by uncompensated system and the feedback compensated system has the worst performance indices.
\end{abstract}

\section{General Terms}

Control Systems

\section{Keywords}

feedback compensated system, Nigeria, PID controller, satellite dish network, series compensated system, stability region, uncompensated system.

\section{INTRODUCTION}

Accurate position control is critical to every satellite dish system, either mobile or stationary. As a means of ensuring that the satellite dishes in the mobile/stationary satellite dish network remain pointed and locked to a desired geostationary satellite at all time appropriate robust position controllers are normally introduced into the system.

The command and control in this work is based on Proportional-Integral-Derivative, PID, controller algorithm. However, the effectiveness of PID controller is largely determined by the amount of delay between the formulation of PID control law and its delivery to the actuator [1]. It was established that the performance of PID controller degrades with increase in time delay. This is because the formulated corrective action is based on the past output and not the current output being corrected [2].
The design of a robust and effective PID controller in a supervisory control configuration of network of mobile nodes with large and variable time delays within Nigeria was considered in [1]. In the work an effective control and delay management of a national area network of mobile vehicles carrying satellite dishes either in fixed position or moving at a maximum speed of $240 \mathrm{~km} / \mathrm{hr}$ within Nigeria was considered. There was remarkable improvement in the compensated system performance when the performance indices for the compensated and uncompensated systems were compared, although the controller element was added to the control loop as series compensation. It has been established that the controller element can be added to control loop as series compensation or feedback compensation [3], [4], [5] but the effects of controller location within the structure of network of mobile satellite dish position control system has not been given serious attention.

This paper presents our work on the investigation of effects of controller location within the structure of national area network of satellite dishes mounted on vehicles in either parking position or moving at a maximum speed of $240 \mathrm{~km} / \mathrm{h}$ within Nigeria on system performance. The central control office, $\mathrm{CCO}$ is assumed to be at Abuja, the data is via Nigcomsat-1R satellite and the mobile nodes are distributed within Nigeria.

The two parameters needed to formulate the control law are the round trip delay, and the plant transfer function. Round trip time delay is the sum of delays from the plant to the satellite, the satellite to the $\mathrm{CCO}, \mathrm{CCO}$ to the satellite, and the satellite back to the plant; or vice versa. Therefore, a model for predicting the end-to-end delays was developed; and the plant's transfer function was empirically determined.

The plant is the Outdoor Unit consisting of a dish, block up converter/low noise block converter, and a jack actuator. The transfer function is determined from the plant total mass, spring constant, and damping coefficient. The round trip delay model is based on calculating the round trip distance divided by the speed of light at $30 \times 10^{9} \mathrm{~m} / \mathrm{s}$.

The three PID parameters required are the proportional gain value, $\mathrm{K}_{\mathrm{p}}$, integral gain value, $\mathrm{K}_{\mathrm{i}}$, and the derivative gain value, $K_{d}$ that guarantee system stability in spite the control action and time-delay. Firstly the acceptable value of $\mathrm{K}_{\mathrm{p}}$ was obtained using root locus method. Then for the determined value of $\mathrm{K}_{\mathrm{p}}$, the region of acceptable stability for the system was graphically determined in the $K_{i}-K_{d}$ plane. Values for $K_{i}$ and $K_{d}$ were determined within the region of stability. The determined values of $K_{p}, K_{i}$ and $K_{d}$ were slotted into the PID controller transfer function. The resulting controller was then 
connected to the system as series compensation and feedback compensation respectively.

The performance indices for the formulated control action is based on time domain performance indices, settling time, $t_{s}$, time to peak overshoot, $t_{p}$, percentage overshoot, P.O, and rise time, $\mathrm{t}_{\mathrm{r}}$, of the composite system dynamic's time response.

After putting together the composite system transfer function for uncompensated, series compensated and feedback compensated systems, they were then subjected to a step input forcing function which yielded time domain performance indices values for these systems using MATLAB as a simulation tool. The uncompensated system's performance indices values form the basis for the determination of PID controller's performance. The obtained time domain performance indices for the uncompensated system, series compensated system and feedback compensated system shows that the series compensated system has better performance followed by uncompensated system and the feedback compensated system has the worse performance indices.

\section{SYSTEM NODAL TRANSFER FUNCTION}

A network node consists of the dish structure and the actuator jack units. The transfer functions of these units are as expressed in equations (1) and (2) respectively [6].

$$
\begin{aligned}
\mathrm{G}_{\mathrm{ds}} & =\frac{2.2578}{\mathrm{~s}^{2}+0.9016 \mathrm{~s}+2.257 \mathrm{a}} \\
\mathrm{G}_{\mathrm{aj}} & =\frac{0.0025}{\mathrm{~s}(1+0.015 \mathrm{~s})}
\end{aligned}
$$

The plant transfer function was determined by connecting the transfer function of (1) and (2) in cascade and is as shown in equation (3)

$$
\begin{aligned}
G_{p} & =\frac{0.0025}{s(1+0.015 s)} \times \frac{2.2578}{s^{2}+0.9016 s+2.2578} \\
& =\frac{3.76}{s^{4}+67.56 s^{2}+62.36 s^{2}+150.52 s}
\end{aligned}
$$

Equations (4) and (5) give the transfer function for both the up and down link time delay respectively.

$$
\begin{aligned}
& \mathrm{G}_{\mathrm{d} 1}=\mathrm{e}^{\mathrm{T}_{\mathrm{d} 1} \mathrm{~s}} \\
& \mathrm{G}_{\mathrm{d} 2}=\mathrm{e}^{\mathrm{T}_{\mathrm{d} 2} \mathrm{~s}}
\end{aligned}
$$

$T_{d 1}$ and $T_{d 2}$ are the up and down link time delay respectively and their values range between 0.2469 seconds and 0.2491 seconds [7].

\section{DESIGN OF PID CONTROLLER}

Given the transfer function of PID controller as in equation (6), PID controller design involve the optimal determination of the three PID parameters $\mathrm{K}_{\mathrm{p}}, \mathrm{K}_{\mathrm{i}}$, and $\mathrm{K}_{\mathrm{d}}$ in such away that the stability of the composite transfer function is still guaranteed and the required predetermined performance specifications are met.

$G_{\text {pid }}(s)=\frac{K_{d} s^{2}+K_{p} s+K_{i}}{s}$ where

$\mathrm{K}_{\mathrm{p}}=$ Proportinal gain

$\mathrm{K}_{\mathrm{i}}=$ Integral gain

$\mathrm{K}_{\mathrm{d}}=$ Derivative gain

$\frac{\theta_{\mathrm{A}}(\mathrm{s})}{\theta_{\mathrm{r}}(\mathrm{s})}=\frac{\mathrm{G}_{\text {pid }}(\mathrm{s}) \mathrm{G}_{\mathrm{p}}(\mathrm{s}) \mathrm{G}_{\mathrm{d}_{1}(\mathrm{~s})}}{1+\mathrm{G}_{\text {pid }}(\mathrm{s}) \mathrm{G}_{\mathrm{p}}(\mathrm{s}) \mathrm{G}_{\mathrm{d}_{1}(\mathrm{~s}) \mathrm{G}_{\mathrm{d}}(\mathrm{s})}}$

$\frac{\theta_{\mathrm{A}}(\mathrm{s})}{\theta_{\mathrm{r}}(\mathrm{s})}=\frac{\mathrm{G}_{\mathrm{p}}(\mathrm{s}) \mathrm{G}_{\mathrm{d} 1}(\mathrm{~s})}{1+\mathrm{G}_{\mathrm{pid}}(\mathrm{s}) \mathrm{G}_{\mathrm{p}}(\mathrm{s}) \mathrm{G}_{\mathrm{d} 1}(\mathrm{~s}) \mathrm{G}_{\mathrm{dz}}(\mathrm{s})}$

It can be seen that the characteristic equations of the transfer functions of equations (7) and (8) are the same, therefore, the same PID controller will stabilise them. Because of this, we need to design just a controller algorithm for both the series compensated and feedback compensated systems.

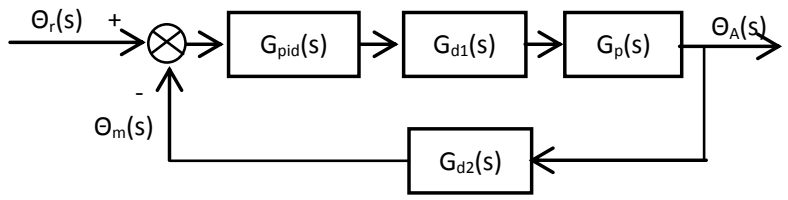

Fig 1: Block Diagram of the Composite Series Compensated System

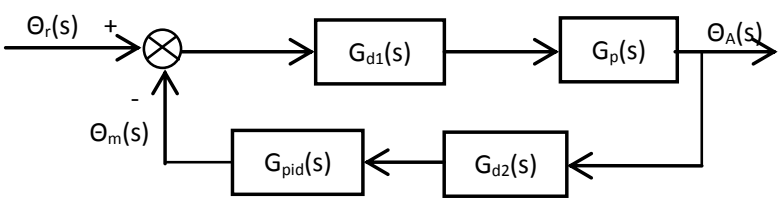

Fig 2: Block Diagram of the Composite Feedback Compensated System

It has been established in [1], [8] that the design of PID controller for any arbitrary order system can be achieved by:

i. Define two stability boundaries in the $\left(\mathrm{K}_{\mathrm{p}}, \mathrm{K}_{\mathrm{i}}\right)$ plane for fixed value of $K_{d}$;

ii. Define two stability boundaries in the $\left(\mathrm{K}_{\mathrm{p}}, \mathrm{K}_{\mathrm{d}}\right)$ plane for fixed value of $\mathrm{K}_{\mathrm{i}}$;

iii. Extract the lines that define the sides of the polygon.

iv. The sides of this polygon define the stability boundary for $\mathrm{K}_{\mathrm{i}}$ and $\mathrm{K}_{\mathrm{d}}$ gains.

The design was carried out via simulation using MATLAB as simulations tool. Firstly, simulation was performed for $\mathrm{K}_{\mathrm{d}}=0$, and $\mathrm{K}_{\mathrm{d}}=2$ respectively in order to obtain the two stability boundaries in the $\left(\mathrm{K}_{\mathrm{p}}, \mathrm{K}_{\mathrm{i}}\right)$ plane as shown in Figure 3.

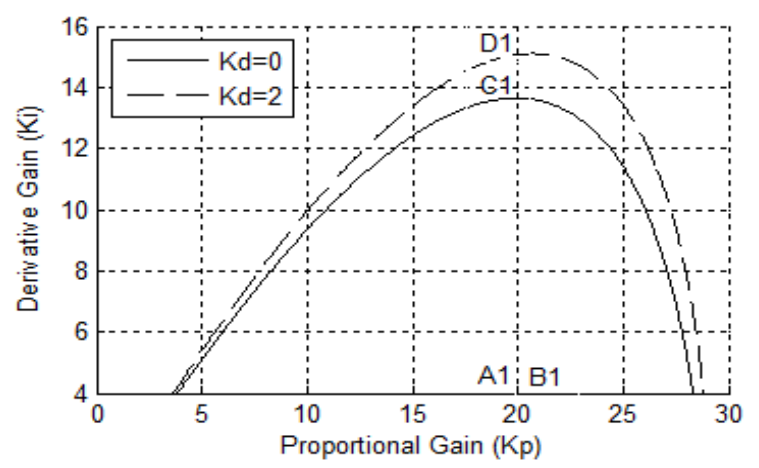

Fig 3: Stability Region in the $\left(K_{p}, K_{i}\right)$ Plane for $K_{d}=0$ And $\mathbf{K}_{\mathrm{d}}=\mathbf{2}$. 
The second simulation was carried out to determine the two stability boundaries in the $\left(\mathrm{K}_{\mathrm{p}}, \mathrm{K}_{\mathrm{d}}\right)$ plane for $\mathrm{K}_{\mathrm{i}}=10$, and $\mathrm{K}_{\mathrm{i}}=15$ respectively as shown in Figure 4.

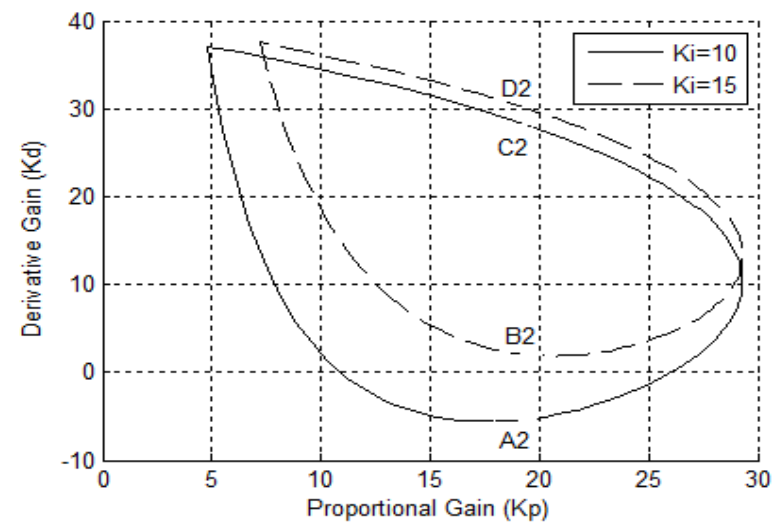

Fig 4: Stability Region in the $\left(K_{p}, K_{d}\right)$ Plane for $K_{i}=10$ and $K_{i}=15$.

The third simulation was carried out to determine the stability polygon for a given value of $K_{p}$. The acceptable value of $K_{p}$ was obtained using root locus method. Then for the determined value of $\mathrm{K}_{\mathrm{p}}, 20$ in this case the region of acceptable system stability was graphically determined in the $\left(\mathrm{K}_{\mathrm{i}}-\mathrm{K}_{\mathrm{d}}\right)$ plane as shown in Figure 5. Given this acceptable region of stability, values for $K_{i}$ and $K_{d}$ were determined for the determined value of $K_{p}$. The performance indices for the

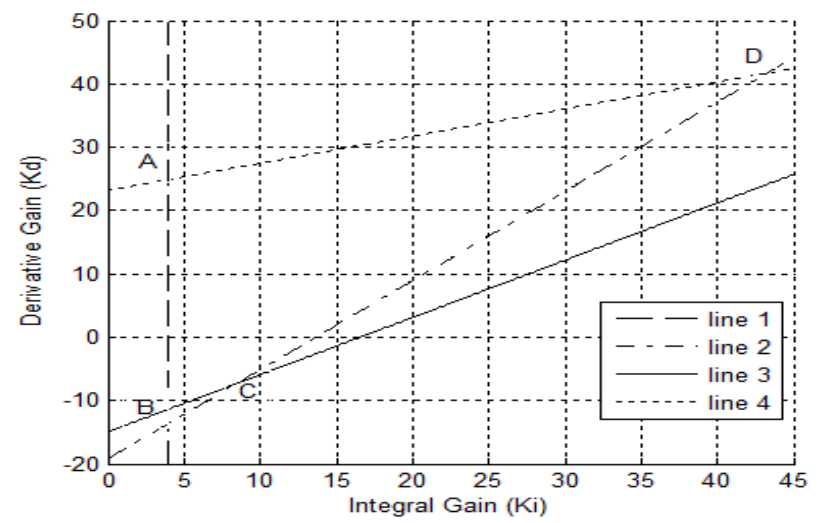

Fig 5: Stability Region in the $\left(K_{i}, K_{p}\right)$ Plane for $K_{p}=20$ in performance indices, settling time, ts, time to peak overshoot, tp, percentage overshoot, P.O, and rise time, tr, of the composite system dynamic's time response.

Therefore, using these determined values of $K_{p}, K_{i}$ and $K_{d}$ the values of the system time domain performance indices were determined for uncompensated, series compensated and feedback compensated systems from the composite system unit step response of Figure 6. In addition, system robustness test was carried out over the entire time delay range.

\section{RESULTS AND DISCUSSION}

The determined $K_{p}$ value was 20 , while the determined optimum value for $K_{i}$ and $K_{d}$ from Figure 5 were 4 and 0 respectively. From Figure 6 the performance indices obtained for the uncompensated system were 85.9 seconds rise time, 350 seconds time to peak overshoot, $0 \%$ percentage overshoot and 154 seconds settling time and that for series compensated system 1.31 seconds rise time, 4.08 seconds time to peak overshoot, 69\% percentage overshoot and 21.2 seconds settling time. Finally, for the feedback compensated system the maximum peak value obtained was 0.06 , this means the system response can never get to the reference input instead it settled finally to 0 value.

The corresponding performance indices for each of the three systems remain constant over the entire time delay range, thus confirming the robustness of these systems within the range of minimum, 0.2469 seconds and maximum, 0.2491 seconds possible time delay obtainable within Nigeria when the CCO is at Abuja.

The uncompensated system's performance indices values form the basis for the determination of PID controller's performance. The obtained time domain performance indices for the uncompensated system, series compensated system and feedback compensated system shows that the series compensated system has the best performance followed by uncompensated system and the feedback compensated system has the worst performance indices.

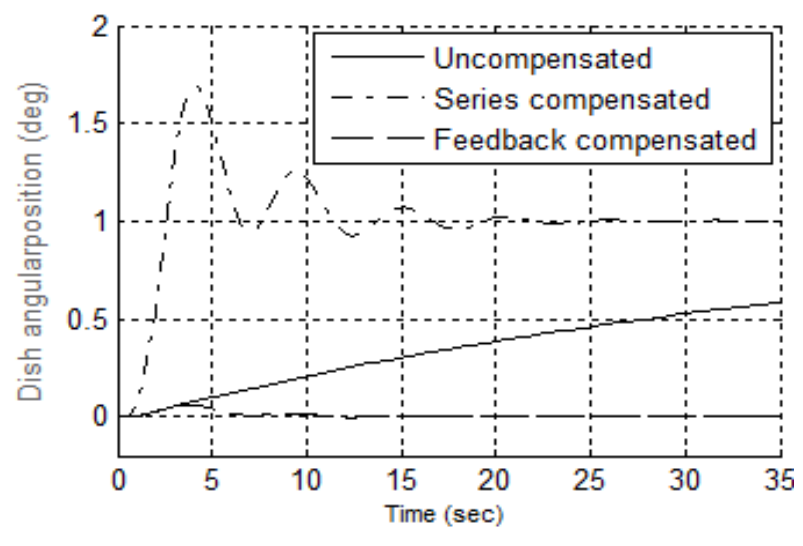

Fig 6: The Unit Step Response of Composite Uncompensated Series Compensated and Feedback Compensated Systems 


\section{CONCLUSION}

The system stability region in the $K_{i}$ and $K_{d}$ plane for both the series and feedback compensated position control system was graphically determined for a predetermined value of $K_{p}$ for controlling centrally the position of network of mobile satellite dishes within Nigeria to point and lock onto NigComSat-1R satellite quickly and precisely with central control office at Abuja was determined. The composite system transfer function for uncompensated, series compensated and feedback compensated systems were also determined. The results obtained from time domain performance indices for the uncompensated system, series compensated system and feedback compensated system shows that the series compensated system has the best performance followed by uncompensated system and the feedback compensated system has the worst performance indices. From these results, we conclude that this class of system should always be series compensated in other to achieve optimum system performance.

\section{REFERENCES}

[1] T. S. Ibiyemi and A. T. Ajiboye, "On PID Controller Design for Mobile Node Network with Variable Delays", International Journal of Science and Advanced Technology, vol.2, No.4, pp. 176-179, 2012.Available at url:

http://www.ijsat.com/view.php?id=2012:April:Volume\% $202 \% 20$ Issue $\% 204$

[2] T. S. Ibiyemi and A. T. Ajiboye, "Robust PID Control of Mobile Satellite Dish Network within Nigeria",
International Journal of Computer Application, vol 41, no. 21, 2012 pp 32; Available at url: http://www.ijcaonline.org/archives/volume41/number21/ 5828-8154

[3] Dorf, R. C. and Bishop, R. H, 2005, Modern Control Systems. Low Price Edition. Pearson Education (Singapore) pte. Ltd.: Delhi, India, pp.564.

[4] Distefano, J. J.; Stubberud, A. R. Williams, I. V. and Rao,K. A, 2007,Feedback and Control Systems. Second Edition. Tata McGraw - Hill Publishing Company Limited, New Delhi, India, Pp. 10.7.

[5] Al-Assadi, S. A. and Al-Chalabi, L. A. M, 1987, "Optimal Gain for Proportional - Integral - Derivative Feedback." IEEE Control Systems Magazine, Pp.16.

[6] T. S. Ibiyemi and A. T Ajiboye, "Robust PID Control of Mobile Satellite Dish Network within Nigeria", International Journal of Computer Application, vol. 41, no. 21, pp.35, 2012. Available at url:

[7] T. S. Ibiyemi and A. T. Ajiboye, "Automatic Tracking of NigComSat-1R Satellite by Dish Network Mounted on Mobile Tele-Medicine Vehicles", International Journal of Engineering Research and Technology (IJERT), vol.1 issue 4, June-2012, Pp1-3.

[8] Ajiboye, A. T. 2012 "Development of Automatic Position Controller for Mobile Satellite Dish Network within Nigeria." Ph.D Thesis, Department of Electrical Engineering, Faculty of Engineering and Technology, University of Ilorin, Ilorin, Nigeria, Pp 53. 